Educación Física y Ciencia, vol. 23, nº1, e158, enero-marzo 2021. ISSN 2314-2561

Universidad Nacional de La Plata.

Facultad de Humanidades y Ciencias de la Educación.

Departamento de Educación Física

\title{
Gosto, importância e participação de meninas e meninos na educação física no ensino médio
}

Preference, importance and participation of girls and boys in the Physical Education High School class

Gusto, importancia y participación de chicas y chicos en Educación Física en la Educación Secundaria

Marcos Roberto So

Instituto Federal de Educação, Ciência e Tecnologia do Sul

de Minas (IFSULDEMINAS), Câmpus Muzambinho.

Universidade Estadual de Campinas (UNICAMP), Brasil

marcos.so@ifsuldeminas.edu.br

iD https://orcid.org/0000-0003-2338-3481

Mariana Zuaneti Martins

Universidade Federal do Espirito Santo (UFES), Brasil

marianazuaneti@gmail.com

iD https://orcid.org/0000-0003-0926-7302

Gilson Rodrigues Santos

Universidade Estadual de Campinas (UNICAMP), Brasil

gio.sts.rodrigues@hotmail.com

(iD) https://orcid.org/0000-0002-1472-2480

Elaine Prodócimo

Universidade Estadual de Campinas (UNICAMP), Brasil

elaine@fef.unicamp.br

iD https://orcid.org/0000-0002-2500-3668

Tatiana Zuardi Ushinobama

Universidade Federal Fluminense - Programa de Pós-

Graduação em Comunicação (PPGCOM), Brasil

tatianazuardi@globo.com

Mauro Betti

Universidade Estadual Paulista (UNESP), Câmpus

Bauru, Brasil

maurobettiunesp@gmail.com

\section{RESUMo:}

O objetivo do estudo é compreender, sob perspectiva discente, a interferência do marcador gênero nas relações dos/as estudantes de Ensino Médio com a Educação Física (EF). Trata-se de uma pesquisa descritiva com 94 alunos e 88 alunas de 8 escolas estaduais de São Paulo (Brasil), que levantou informações de gosto, importância e participação na disciplina EF, a partir de aplicação de questionário estruturado. Os resultados indicam que meninos atribuem maior importância, gostam e participam mais do que as meninas. Contudo, não é possível afirmar que meninas desgostam, não participam e não atribuem importância. Em cotejo com a literatura, a participação das alunas na EF, além do fator gosto, está concatenada a obrigação ou via "obediência-subversiva" no ambiente ambíguo escolar, de discursos explícitos de igualdade de condições e de práticas implícitas segregacionistas de gênero; por sua vez, a referida ambiência implícita favorece a "colonização" de meninos nas aulas de EF. Concluímos que são os docentes (homens e mulheres) que podem problematizar a desigualdade e ajudar a instituir uma EF com equidade de gênero.

Palavras-Chave: Gênero, Ensino Médio, Educação Física.

\section{Recepção: 31 Julho 2020 | Aprovação: 16 Dezembro 2020 | Publicação: 01 Fevereiro 2021}

Cita sugerida: So, M. R., Zuaneti Martins, M., Santos, G. R., Ushinohama, T. Z. y Betti, M. (2021). Gosto, importância e participação de meninas e meninos na educação física no ensino médio. Educación Física y Ciencia, 23(1), e158. https://doi.org/10.24215/23142561e158 


\begin{abstract}
:
The aim of this study is to understand, from the student's perspective, the interference of gender marker in High School students in relation to Physical Education (PE). This is a descriptive study with 94 boys and 88 girls from 8 public schools of São Paulo State (Brazil), which raised information on preference, importance and participation in PE classes, through the application of a structured questionnaire. The results indicate that boys give greater importance to like and participate more in the class than girls. However, it is not possible to say that girls dislike it, do not participate and do not give importance to it. Research in the literature shows that the participation of students in PE, beyond preference, is associated with the obligation or via "subversive obedience" in the ambiguous school environment, with explicit speeches of equal conditions and implicit gender segregationist practices. On the other hand, the implicit environment supports the "colonization" of boys in PE classes. We conclude that teachers (men and women) are the ones who can problematize inequality and assist students to establish gender equity PE.
\end{abstract}

KEYWORDS: Gender, High School, Physical Education.

\title{
INTRODUÇÃO
}

A influência ${ }^{1}$ do marcador de gênero ${ }^{2}$ - depreendido como uma unidade de análise das relações históricas e socioculturais erigidas em torno dos modos de agir, pensar e expressar de meninas e meninos (López, 2014) - tem sido cada vez mais recorrente nas discussões sobre as oportunidades de adesão e permanência nas práticas corporais na Educação Física (EF) (Goellner, 2013; Jacoby \& Goellner, 2020). As investigações nesse contexto têm apontado para aspectos como: a) a forma como o marcador de gênero afeta as práticas esportivas ao longo da vida de mulheres e homens (Pnud, 2017); b) a marginalização da prática esportiva feminina (Goellner, 2013); c) a menor participação de mulheres em programas de atividades físicas e esportivas (Hallal, Knuth, Cruz, Mendes \& Malta, 2010; Ferreira et al.; 2018); d) o declínio da participação de meninas nas práticas esportivas durante a juventude, em especial em regiões mais pobres (Corder et al., 2015), entre outros. Em vista disso, depreendemos que é necessário um olhar mais sensível e crítico em relação às influências do marcador de gênero quando observamos como meninos e meninas se engajam com as práticas corporais no contexto da EF escolar.

Conceitualmente, por gênero, referimo-nos ao caráter estritamente cultural das diferenças percebidas entre homens e mulheres, como apontado por Joan Scott (1995). O marcador de gênero influencia o engajamento com as práticas corporais não por conta de supostas diferenças anátomo-fisiológicas entre homens e mulheres, mas, sobretudo, como resultado de discursos (ou práticas discursivas) que constroem nossa visão sobre essa diferença e desigualdade e informam que algumas atividades seriam inadequadas para meninas ou para meninos (Daolio, 2006). Na prática esportiva realizada por mulheres, por exemplo, discursos segregacionistas repercutiram, ao longo do século XX, em mitos de uma passividade feminina, de um ideal de delicadeza e de feminilidade que seguiam na contramão do engajamento com determinadas práticas esportivas (Goellner, 2003). No Brasil, tais discursos levaram à proibição da prática de modalidades esportivas como futebol, rúgbi e lutas para mulheres de 1941 a 1979 (Goellner, 2003). Para Goellner (2005), embora houvesse proibições e interdições, a prática dos esportes supramencionados realizada por mulheres não era inexistente, pois elas, agenciaram, negociaram e transgrediram os diversos discursos segregacionistas e discriminatórios. Em vista disso, entendemos que, embora determinadas características de gênero tenham contribuído (e ainda contribuem) para o afastamento das mulheres de várias práticas corporais, elas não são, categoricamente, determinantes para esse distanciamento. Portanto, a resistência e a transgressão também são possibilidades de agenciamento diante dos vários discursos segregacionistas da participação feminina nas mais diversas práticas corporais.

Considerando que o engajamento, o hábito e o gosto pelas práticas corporais se constroem durante a infância e juventude, um olhar para a participação de meninos e meninas nas aulas de Educação Física pode contribuir para a compreensão da constituição das diferenças de gênero e com um trabalho pedagógico 
com equidade (Del Castillo-Andrés, Campos-Mesa \& Ries, 2013). Neste sentido, várias investigações já tematizaram o marcador de gênero na disciplina escolar de EF. Entre outros aspectos, debruçaram-se sobre a forma pela qual este marcador interfere na forma de participação nas aulas de EF, nas diferenças no protagonismo entre estudantes meninas e meninos nas aulas desta disciplina escolar (Altmann, 1998; Jacó, 2012; Uchoga \& Altmann, 2016); no silenciamento sobre a temática de gênero nas aulas e, por conseguinte, na necessidade de abordá-la (Jesus \& Devide, 2006); na construção de feminilidades e masculinidades em brincadeiras escolares (Wenetz \& Stigger, 2006); no bullying entre meninas e meninos na EF escolar (Mattos \& Jaeger, 2015); nas implicações envolvidas nas percepções dos professores sobre aulas mistas ou separadas (Dornelles \& Fraga, 2009), dentre outros.

No ensejo desses estudos e discussões, acreditamos que a perspectiva discente em relação à EF escolar e a temática de gênero possam contribuir com a melhoria do ensino dessa disciplina escolar, como defendem Azzarito \& Solomon (2005). Deste modo, um dos aspectos a ser considerado refere-se às relações de sentido que as estudantes e os estudantes comunicam aos professores e/ou professoras sugerindo e/ou indicando novas possibilidades no âmbito do "saber-ensinar" condizente com uma equidade de gênero. À vista disso, o quadro epistemológico ideado e desenvolvido por Bernard Charlot (2000; 2005), que trata da noção de "relação com o saber", pode também contribuir com esta temática. Embora o autor não aborde o marcador de gênero nos e nas estudantes, podemos vislumbrar que o marcador social de gênero interfere nas experiências pessoais de "relação com o saber", produzindo articulações de preferências, exclusões e/ou de desigualdades (Marrero, 2007; Charlot, 2009).

Nesse pano de fundo, sob aporte da noção da relação com o saber de Charlot e do tema gênero, questionamos os sentidos e mobilizações dos e das estudantes na EF: (i) qual é o gosto de meninas e meninos pelas aulas de EF?; (ii) qual a importância atribuída pelos e pelas estudantes à EF?; (iii) como o marcador de gênero interfere na participação discente nas aulas desse componente curricular?; (iv) como os elementos gosto, importância e participação se expressam nos diferentes anos do Ensino Médio (EM) em meninas e meninos? No intuito de obter respostas às questões supramencionadas, estabelecemos como objetivo do presente estudo compreender, sob enfoque da perspectiva discente, a interferência do marcador de gênero nas relaçóes dos e das estudantes de EM com a disciplina escolar de EF.

\section{MÉTodo}

A pesquisa consiste numa abordagem de tipo descritiva e exploratória. Trata-se de um levantamento de campo, com dados de natureza quantitativa e um grau de controle não experimental (Gil, 2010). A técnica de pesquisa foi a documentação direta usando como instrumento de coleta de dados um questionário estruturado contendo 17 questões, conforme indicações de Marconi e Lakatos (2017). Como a atual investigação é parte de uma pesquisa maior ${ }^{3}$, apresentaremos, neste artigo, os resultados e interpretações de 5 questões fechadas relacionadas às temáticas de gosto, importância e participação. A saber: "quais são as três disciplinas (matérias) da escola que você mais gosta?"; "qual a sua opinião sobre as aulas de EF?"; "quais são as três disciplinas (matérias) da escola que você considera mais importantes?"; "você acha que as coisas que você aprendeu na EF são importantes para a sua vida?"; "quanto a sua participação nas aulas de EF, você participa...”.

Participaram da pesquisa 182 discentes do EM sendo: (i) 94 do sexo masculino e 88 do sexo feminino ; (ii) 62 alunos/as do $1^{\circ}$ ano; $55 \mathrm{do} 2^{\circ}$ ano e $65 \mathrm{do} 3^{\circ}$ ano. Este grupo é oriundo de 8 escolas públicas da rede estadual da região centro-oeste do estado de São Paulo, Brasil. As redes escolares de ensino estão localizadas nos municípios: Alfredo Marcondes, Bauru, Jaú, Macatuba, Penápolis, Santo Expedito e São Manuel. A escolha das escolas se deu por critério de acessibilidade e a amostragem dos/as participantes do estudo foi composta por $5 \%$ dos/as alunos/as de todas as turmas das instituições, selecionados/as por sorteio. Esta investigação 
foi aprovada no Comitê de Ética em Pesquisa da Universidade Estadual Paulista (UNESP), sob o processo n. 13142/46/01/12.

Os dados foram organizados em tabelas e gráficos (Marconi \& Lakatos, 2017) e a análise foi realizada por meio da triangulação de dados (Flick, 2009). Nesse sentido, os resultados do levantamento de campo foram confrontados com resultados de outras investigações e com as reflexões suscitadas pelas leituras de outros estudos. Destarte, da triangulação foram construídas três categorias temáticas: gosto, importância e participação.

\section{Resultados E Discuss Ão}

Como apontado, os resultados estão organizados nos grupos: (i) gosto, (ii) importância, e (iii) participação. No primeiro caso, procuramos descrever o quanto os estudantes e as estudantes gostam das aulas de EF e contrastar com o gosto pelas demais disciplinas curriculares. Vale ressaltar que "gostar" remete ao prazer, àquilo que é desejável, uma "aspiração primeira" (CHARLOT, 2000). Portanto, observar o nível de gosto dos e das estudantes mostra-se um passo inicial para compreender a sua disponibilidade pessoal em mobilizar-se para algum saber.

A essa dimensão acrescenta-se, no segundo momento, a relação de importância da EF para a vida dos meninos e das meninas e a importância em comparação às demais disciplinas escolares. Esse aspecto contribui para o entendimento do sentido da EF para os e as estudantes. Para Charlot (2000), faz sentido para um sujeito qualquer objeto, seja este, "um 'conteúdo de pensamento', uma atividade, uma relação, um lugar, uma pessoa, uma situação, etc., que podem inscrever-se nesse conjunto de relações que o sujeito é” (p. 82). Ainda conforme o autor, para "fazer sentido" não necessariamente precisa ter um valor positivo ou negativo. Isto é, a EF com baixa importância para estudantes também é uma forma de atribuir sentido. A única exigência do "sentido" é que ela precisa considerar o "sujeito enquanto dinâmica do desejo". Por este motivo, a categoria gosto não pode ser observada apenas como desejo, mas também como parte integrante do sentido que os e as estudantes atribuem, já que "não há sentido, senão do desejo" ${ }^{4}$ (Charlot, 2000, p. 57).

As dimensões de sentido e significado podem produzir a mobilização para uma atividade. A fim de observar essa dimensão, uma terceira análise retratou a participação de meninas e meninos nas aulas de EF, isto é, buscou compreender como o marcador de gênero interfere na efetiva mobilização pela atividade de participar das aulas, bem como o nível em que os e as estudantes se colocam em movimento para aprender. Posteriormente, desenvolvemos uma análise a partir da síntese dos dados do atual estudo em relação com as ideias de discurso explícito e discriminação implícita na escola e na EF.

\section{Gosto}

Quem gosta, gosta de alguém ou de algo. Gostar é um verbo transitivo indireto que necessita de um complemento que remete à apreciação, ao amar, ao sentir prazer, ao agradável (Houaiss, 2009). Destarte, indagamos: o marcador de gênero está relacionado aos gostos das estudantes e dos estudantes para com a disciplina curricular EF? Assim, primeiramente, apresentaremos o gosto da EF de modo comparativo com outras disciplinas escolares. Nesse sentido, questionamos os e as estudantes: "quais são as três disciplinas (matérias) da escola que você mais gosta?”. A tabela 1 ilustra as respostas. 
TABELA 1 - Atribuição de gosto para as disciplinas do EM

\begin{tabular}{l|cccccccc}
\hline \multicolumn{1}{c}{ Atribuição de gosto para disciplina de EF em cada ano do EM estratificado pelos sexos masculino } \\
e feminino
\end{tabular}

Fonte: autoria própria

Para meninas e meninos, a EF é a disciplina escolar preferida, superando outras que possuem grande status social como as disciplinas de Matemática e Língua Portuguesa. Ademais, nota-se uma larga vantagem do gosto pela EF em comparação à segunda disciplina curricular mais apreciada tanto entre as meninas quanto entre os meninos. Todavia, ao aumentar a lente de análise exclusivamente para a EF, observa-se que uma maior quantidade de meninos (65\%) elegeu a EF como uma das três disciplinas mais apreciadas, em contraste aos $48 \%$ manifestadas pelas meninas.

Se as meninas esboçam um gosto não-equivalente ao dos meninos, também é possível aventar como o gosto sob o marcador de gênero varia ao longo dos anos do EM. Ainda na análise da tabela 1, a EF é de gosto predominantemente dos meninos, destacando-se em primeiro lugar em todos os anos e, ademais, com ampla vantagem para a Matemática (a segunda disciplina na ordem da atribuição de gosto). Essa diferença é mais proeminente entre o $1^{\circ}$ e o $2^{\circ}$ ano, superando os 20\%. Entretanto, essa preferência pela EF não se repete entre as estudantes, para quem, a EF somente é considerada a primeira na ordem de gosto no $2^{\circ}$ ano do EM; sendo que, a diferença da primeira para a segunda (a disciplina de Arte) não é tão discrepante quanto o ocorrido entre os estudantes. No $1^{\circ}$ ano, a EF é a segunda na ordem de gosto entre as estudantes, $3 \%$ a menos que a primeira (Matemática). Além disso, no $3^{\circ}$ ano é somente a quarta, atrás das disciplinas de Biologia, Matemática e Português.

Em síntese, os dados totais e estratificados por ano escolar sugerem uma distinção na ordem de gosto entre meninos e meninas, como também notaram Hernández-Alvarez, López-Crespo, Martínez-Gorroño, LópezRodríguez \& Álvarez-Barrio (2010) e Ferreira, Graebner e Matias (2014). Analisando sob a perspectiva de uma "leitura positiva" do fenômeno educativo (Charlot, 2000), é importante destacar que apesar da EF não figurar entre as disciplinas que elas mais gostam no $1^{\circ}$ e no $3^{\circ}$ ano, não se encontra entre as disciplinas escolares que mais desgostam. Este resultado informa que a preferência das estudantes pelas aulas de EF não é unânime. Estudos anteriores sobre o tema descrevem fatores que têm afastado as estudantes de uma valoração positiva da EF. Dentre tais fatores estão: a falta de confiança em suas próprias habilidades, vergonha de se expor frente 
ao olhar e julgamento alheio, vergonha de se arriscar em atividades que ainda não dominam e a própria forma como os meninos dominam o espaço das aulas de EF (Oliver \& Hamzeh, 2010; Uchoga \& Altmann; 2016; Okely et al., 2017; So, Martins \& Betti; 2018). Desta forma, podemos inferir desses indicativos da literatura de que um, ou a combinação de vários desses fatores, possa ter interferido nas preferências relatadas pelas alunas.

Em segundo momento, para analisar especificamente a atribuição de gosto para disciplina de EF foi feita a seguinte questão: "Qual a sua opinião sobre as aulas de EF?" A tabela 2 mostra as respostas à questão:

TABELA 2 - Juízo de gosto em relação à disciplina curricular de EF de estudantes de EM estratificado por sexo.

\begin{tabular}{lcccccccc}
\hline \multirow{2}{*}{ Resposta } & \multicolumn{2}{c}{ Total } & \multicolumn{2}{c}{$\mathbf{1}^{\circ}$ ano } & \multicolumn{2}{c}{$\mathbf{2}^{\circ}$ ano } & \multicolumn{2}{c}{$\mathbf{3}^{\circ}$ ano } \\
\cline { 2 - 9 } & Meninas & Meninos & Meninas & Meninos & Meninas & Meninos & Meninas & Meninos \\
\hline Gosto muito & $49 \%$ & $70 \%$ & $56 \%$ & $83 \%$ & $43 \%$ & $60 \%$ & $48 \%$ & $65 \%$ \\
\hline $\begin{array}{l}\text { Gosto } \\
\text { mais/menos }\end{array}$ & $42 \%$ & $24 \%$ & $33 \%$ & $14 \%$ & $47 \%$ & $32 \%$ & $45 \%$ & $29 \%$ \\
\hline Gosto pouco & $9 \%$ & $4 \%$ & $11 \%$ & $3 \%$ & $10 \%$ & $8 \%$ & $6 \%$ & $3 \%$ \\
\hline Não Gosto & $0 \%$ & $0 \%$ & $0 \%$ & $0 \%$ & $0 \%$ & $0 \%$ & $0 \%$ & $0 \%$ \\
\hline Detesto & $0 \%$ & $1 \%$ & $0 \%$ & $0 \%$ & $0 \%$ & $0 \%$ & $0 \%$ & $3 \%$ \\
\hline Branco/Nulo & $0 \%$ & $0 \%$ & $0 \%$ & $0 \%$ & $0 \%$ & $0 \%$ & $0 \%$ & $0 \%$ \\
\hline
\end{tabular}

Fonte: autoria própria

Observamos que grande parte dos e das estudantes participantes da pesquisa gostam deste componente curricular, independente se atribuem como critério "gosto muito" ou "gosto mais ou menos". Contudo, a opção de resposta "gosto muito" reforça a distinção na ordem de gosto entre os dois grupos. No geral, os meninos são maioria na alternativa "gosto muito" (70\%), diferentemente das meninas, em que o mesmo quesito alcança aproximadamente a metade das respostas. Por sua vez, em tendência "espelhada”, a alternativa "gosto mais ou menos" apresenta-se em maior número nas estudantes em comparação com os estudantes. Por fim, na opção "gosto pouco", as estudantes também são em maior número, porém, a diferença entre o grupo de meninas e meninos não ultrapassa 5\%. Todavia, vale ressaltar que, mesmo que haja diferença na atribuição de gosto entre os e as estudantes, o gosto delas para a EF ainda se encontra com uma alta percentagem.

Essa satisfação com a Educação Física pelas estudantes também é citada em outros estudos. Betti e Liz (2003), em estudo com 151 meninas, apontaram que 75\% manifestaram que "gostam" ou "gostam muito" da disciplina. Neste estudo, $42 \%$ das participantes declararam "gostar muito" indicando valores que se aproximam ao apresentado na presente investigação. Por outro lado, uma possível justificativa para o gosto não ter sido elevado como decorre entre os estudantes é apresentado por Martinelli, Merida, Rodrigues, Grillo \& Souza (2006) que realizou uma pesquisa com alunas de EM que não gostavam da EF. O principal motivo de desgosto apontado pelas participantes estava associado a pouca diversidade de conteúdo impedindo-as de ter uma relação de "prazer" com a EF.

O indício de gosto maior dos estudantes também permanece quando analisamos os resultados em cada ano escolar do EM. Contudo, dois aspectos chamam a atenção. Em primeira análise, constatamos que é no $1^{\circ}$ ano que os e as estudantes atribuem maior gosto pela EF. Em segunda análise, notamos que a diferença na percentagem entre os gêneros é mais acentuada neste mesmo ano escolar, especialmente porque os meninos parecem "gostar muito" mais da disciplina em comparação com o $2^{\circ}$ e o $3^{\circ}$ ano do EM. Isto é, se compararmos o ano de entrada e o de saída no EM, nota-se que o quesito "gosto muito" possui maior declínio nos estudantes em comparação as estudantes. Porém, este resultado, em decorrência de sua característica descritiva, não consegue responder os motivos que levam a esta tendência decrescente. Em suma, a pesquisa 
indica a necessidade de outras investigações que proponham desenhos metodológicos que indaguem os e as discentes por meio de entrevistas, histórias de vida, grupos focais, etc., sobre tais motivos.

Outra observação é que as estudantes responderam com maior frequência o quesito "gosto pouco", tanto no resultado geral como no estratificado por ano escolar. Tal comportamento indica duas observaçóes: a primeira é que apenas um contingente pequeno entre todos os e todas as estudantes relata um distanciamento maior de preferências com a EF, demonstrando que essa disciplina tem uma maior chance de mobilização discente, consequentemente, o fracasso escolar seria menos acentuado nela. Não obstante, esse contingente que menciona "gostar pouco" não pode ser negligenciado e, dentre ele, a presença de meninos contribui para que percebamos que a forma como o gênero interfere nas preferências não é uniforme e estanque. De fato, Judith Butler (2004) já indicava que as masculinidades e as feminilidades são plurais e não podem ser encapsuladas num determinado estereótipo. Isto não significa, resumidamente, que a maioria das estudantes tenha menos afinidade com as aulas de EF, ao invés, aponta que há feminilidades mais "ativas" (ou predispostas às práticas corporais) e masculinidades menos “ativas” (Oliver \& Hamzeh, 2010).

\section{Importância}

Um dos critérios que nos orienta para a tomada de decisões é o juízo de importância, como nos encoraja a pensar Leitão (2019). Isto é, a análise valorativa de algo em comparação com outras coisas nos faz preferir ou preterir determinado objeto, saber, disciplina curricular etc. Nesta pesquisa, em especial, a intenção é compreender como os estudantes e as estudantes avaliam a importância da EF frente às outras disciplinas curriculares e, também, como ajuízam a EF para a vida. Nessa direção, aos e às participantes da pesquisa foram feitas duas indagações: "(1) Quais são as três disciplinas (matérias) da escola que você considera mais importantes?” e “(2) Você acha que as coisas que você aprendeu na EF são importantes para a sua vida?” A tabela 3 apresenta a importância da EF comparada com as demais disciplinas curriculares do EM:

TABELA 3 - Importância atribuída às disciplinas curriculares de EM.

\begin{tabular}{ccccc}
\hline Disciplina & \multicolumn{2}{c}{ Meninas } & \multicolumn{2}{c}{ Meninos } \\
\cline { 2 - 5 } Matemática & $\mathbf{\%}$ & Ord. & $\%$ & Ord. \\
\hline Português & $93 \%$ & $2^{\circ}$ & $93 \%$ & $1^{\circ}$ \\
\hline Geografia & $94 \%$ & $1^{\circ}$ & $88 \%$ & $2^{\circ}$ \\
\hline Biologia & $24 \%$ & $4^{\circ}$ & $16 \%$ & $5^{\circ}$ \\
EF & $26 \%$ & $3^{\circ}$ & $13 \%$ & $7^{\circ}$ \\
\hline História & $\mathbf{1 5} \%$ & $\mathbf{5}^{\circ}$ & $\mathbf{2 3} \%$ & $\mathbf{3}^{\circ}$ \\
\hline Inglês & $15 \%$ & $6^{\circ}$ & $17 \%$ & $4^{\circ}$ \\
\hline Física & $10 \%$ & $8^{\circ}$ & $15 \%$ & $6^{\circ}$ \\
\hline Química & $15 \%$ & $7^{\circ}$ & $9 \%$ & $8^{\circ}$ \\
\hline Filosofia & $3 \%$ & $9^{\circ}$ & $6 \%$ & $9^{\circ}$ \\
\hline Sociologia & $3 \%$ & $10^{\circ}$ & $4 \%$ & $10^{\circ}$ \\
\hline Ciências & $1 \%$ & $11^{\circ}$ & $2 \%$ & $11^{\circ}$ \\
Arte & $0 \%$ & $12^{\circ}$ & $2 \%$ & $12^{\circ}$ \\
Branco/Nulo & $0 \%$ & $13^{\circ}$ & $2 \%$ & $13^{\circ}$ \\
\hline
\end{tabular}

Fonte: autoria própria

Conforme os resultados da tabela 3, constatamos uma diferença na forma como os estudantes e as estudantes se relacionam com a importância da EF. Deste modo, para as estudantes, a EF é a quinta na ordem de importância (15\%); já entre os estudantes, está na terceira posição com $23 \%$, sendo superada apenas 
por Matemática e Língua Portuguesa, disciplinas hegemônicas no currículo escolar (quanto à desigualdade de carga horária, a exclusividade como conteúdo de avaliações de larga escala etc.). A diferença entre as estudantes e os estudantes é que, além da valoração da Língua Portuguesa e Matemática, as meninas acrescentam a Biologia e a Geografia à frente da EF. Estes dados compactuam com o observado no estudo de Betti e Liz (2003), que constatou que a EF foi declarada em sexto lugar na ordem de importância para as estudantes do Ensino Fundamental, sendo superadas pelas disciplinas de Matemática, Português, Inglês, Ciências e Geografia. E, inferimos que, em comparação com as demais disciplinas escolares, os estudantes atribuem maior importância à EF em relação às meninas.

Em contrapartida, outra forma de olhar para essa questão é analisar como a importância da EF é manifestada entre meninas e meninos ao longo dos anos do EM. A figura 1 mostra a frequência e a ordem de importância para a disciplina de EF em cada ano do Ensino Médio.

Figura 1. Importância da disciplina EF para meninas e meninos ao longo dos anos de escolarização do EM

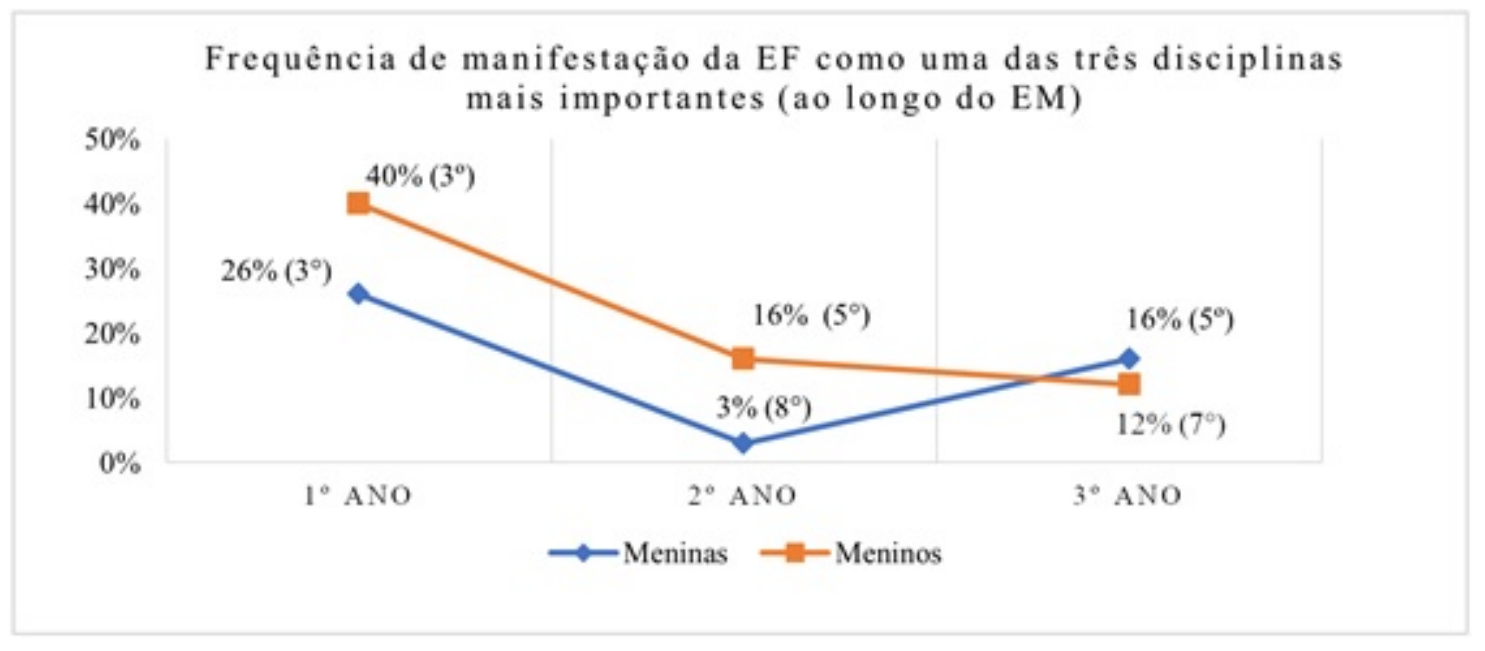

Fonte: autoria própria

Se compararmos o ano de ingresso com o último ano do EM, notamos que o nível de importância da EF decai tanto entre as estudantes quanto entre os estudantes. Conforme a figura 1 , no $1^{\circ}$ e no $2^{\circ}$ ano, os meninos atribuem mais importância que as meninas. Contudo, no $3^{\circ}$ ano a diferença se inverte, os meninos possuem frequência de $12 \%$ e as meninas $16 \%$. Para além da diferença entre os e as estudantes, há que se destacar que o interesse decai para ambos quando se compara o ano de entrada e saída do EM.

Essa inversão de ordem de importância pode ser interpretada à luz da discussão empreendida por Carvalho (2015), acerca da relação das e dos jovens da periferia com a escola. A autora destaca que as jovens costumam ter projetos mais sólidos do ponto de vista profissional, o que as fazem tomar a escolarização com mais seriedade, em busca da concretização desses projetos, via de regra, permeados pela expectativa de acesso ao Ensino Superior. Entrementes, os jovens, embora possuam projetos profissionais, não têm de forma estruturada o caminho para atingi-los. Deste modo, esses rapazes, sobretudo no EM, declinam ainda mais a importância dada à escolarização formal em função de conciliar estudos com um trabalho/emprego bem distante das expectativas profissionais iniciais. A partir desse olhar, portanto, podemos interpretar que para os estudantes o declínio de importância da EF, talvez acompanhe um declínio do interesse pela escolarização de modo geral, dado que a EF parece ser uma disciplina de grande afeto para os meninos.

Comparando o "gosto" e a "importância" dos e das estudantes, nota-se que tanto nos resultados totais quanto os estratificados por ano escolar, o gosto não determina a importância, mas pode influenciá-la em algum grau. Se compararmos a tabela 1 com a tabela 3, percebemos que a EF é, respectivamente, a primeira e terceira na ordem de gosto dos meninos e das meninas; ao passo que, na ordem de importância, a disciplina 
posiciona-se em terceira e em quinta, respectivamente para os e as estudantes. Ao estratificar os resultados para cada ano escolar, destacam-se os resultados das meninas do $2^{\circ}$ ano para quem a EF é a disciplina que mais gostam e, simultaneamente, a oitava disciplina mais importante. Da mesma forma, os estudantes atribuem o primeiro lugar à EF na ordem de gosto em todos os anos escolares do EM, porém, na ordem de importância posicionam a disciplina em terceira, sexta e sétima posição, no $1^{\circ}, 2^{\circ}$ e $3^{\circ}$ ano do EM, respectivamente. Este comportamento dos resultados sinaliza que gostar (prazer) não é uma relação de causa-efeito para a importância (juízo de valor), tanto para os estudantes quanto para as estudantes. Sendo assim, os resultados indicam que meninos e meninas gostam de EF, mas sua importância é intermediária.

Não obstante, ambos os grupos, ao considerarem especificamente os saberes ligados à EF, reconhecem seu valor, conforme a questão: "você acha que as coisas que você aprendeu na EF são importantes para a sua vida?". A figura 2 mostra os resultados dos participantes a esta indagação.

Figura 2. Importância da EF para a sua vida

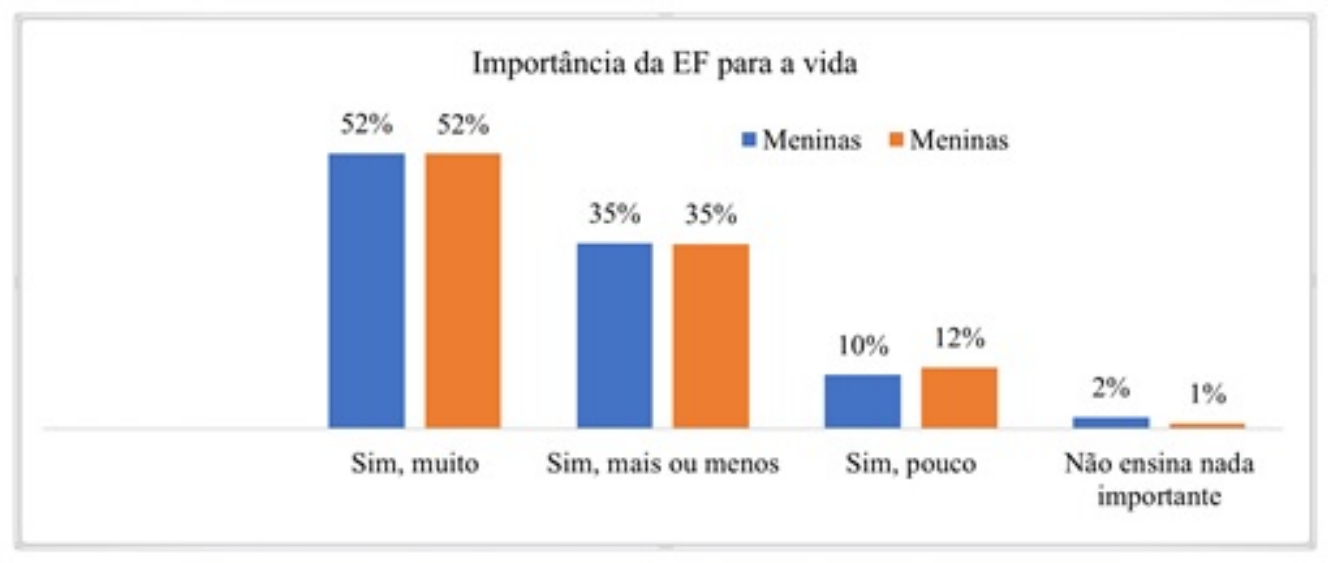

Fonte: autoria própria

A importância da EF para a vida na perspectiva dos e das discentes possui um grau de intensidade similar. Ambos grupos atribuem importância de 52\% para "muito", 35\% para "mais ou menos" e possuem valores aproximados nas categorias "um pouco" e "não ensina nada importante". Logo, além de afirmar que ambos atribuem o mesmo grau de importância à EF, a maioria das estudantes e dos estudantes acredita que a disciplina é importante de algum modo para suas vidas. Este novo alento à importância indica que alunas e alunos atribuem um grande valor para a EF, especialmente se somarmos as categorias que apresentam o quesito "sim", porém, tal valoração parece não superar a importância dada a certas disciplinas escolares.

Ainda é possível analisar o contraste entre o gosto pelas aulas (tabela 2) e a importância da EF para a vida (figura 3). Entre os estudantes, 70\% manifestaram "gostar muito" das aulas, porém, em frequência menor, $52 \%$ mencionaram que a EF é "muito importante" para a vida. Por outro lado, $49 \%$ das meninas afirmaram "gostar muito" da disciplina, ao passo que $52 \%$ acreditam ser "muito importante" para a vida. Nota-se, destarte, que há uma coerência no grupo das discentes em gostar e atribuir importância da EF para a vida e um descompasso desses elementos entre os discentes. Em suma, este dado compactua com estudos anteriores, de que o gosto não está, no mesmo grau, condicionado à importância e vice-versa.

\section{Participação}

As categorias anteriores exploraram os sentidos dos e das estudantes com a EF. Isto é, o gosto e importância são categorias relacionadas aos motivos que levam a adentrar ou a evadir do processo de aprendizagem. Aprender, imprescindivelmente, depende de uma atitude, de um inclinar-se, de colocar-se 
em movimento interior ("reunir esforços") para uma atividade. Para Charlot (2000), essa atitude é a mobilização. Portanto, "mobilizar-se em uma atividade" na EF seria participar efetivamente das aulas.

À vista disso, no âmbito da EF uma das principais maneiras de observar a mobilização em uma atividade se dá a partir da participação dos e das estudantes na aula e da documentação (registro) dessa participação. É por este motivo que a atual categoria é singular, pois pode revelar se os sentidos (razões de agir - gosto e importância) coadunam com a atividade das aulas. Diante disso, questionamos: "quanto a sua participação nas aulas de EF, você participa...” A figura 3 elucida a resposta dos e das estudantes ao questionamento.

Figura 3. Participação discente nas aulas de EF

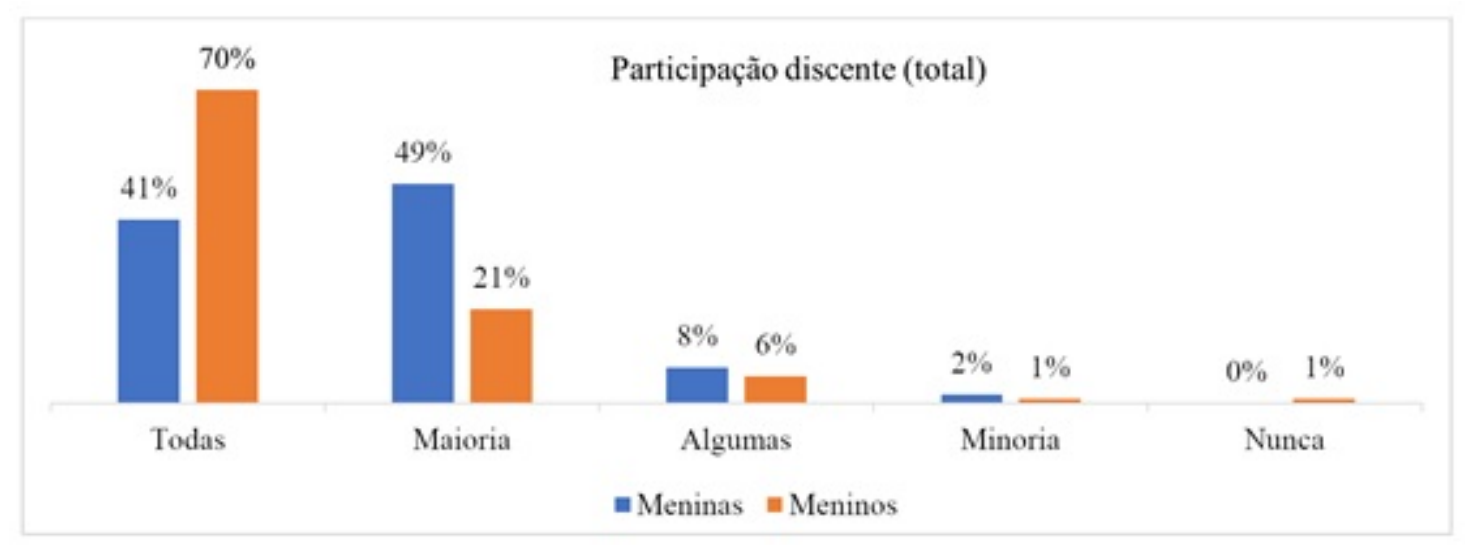

Fonte: autoria própria

Os resultados apontam que tanto as estudantes quanto os estudantes participam da maioria das aulas de EF. Se somarmos as duas primeiras categorias, constatamos que $90 \%$ e $91 \%$ das meninas e dos meninos, respectivamente, participam de "todas" ou da "maioria" das aulas. Todavia, se focarmos a lente de análise para o comportamento destes quesitos, nota-se uma relação oposta. Enquanto $70 \%$ dos discentes declararam participação em "todas" as aulas, o grupo feminino representa $41 \%$. Por outro lado, a categoria "maioria" possui tendência inversa, com maior parcela das estudantes (49\%) em comparação ao grupo dos meninos (21\%). Em síntese, os dados indicam que há uma distinção no nível de participação nas aulas de EF no EM, apontando maior participação dos meninos com expressiva diferença no quesito "todas as aulas".

Uma tendência comum a ambos os grupos é a redução da participação em "todas" as aulas ao longo do EM. Ao compararmos o ano de entrada e de saída no EM, constatamos a tendência da não participação em todas as aulas. No $1^{\circ}$ ano, os estudantes possuem $80 \%$ de participação em todas as aulas, mas no $3^{\circ}$ ano o percentual cai para $59 \%$. Enquanto isso, $48 \%$ das discentes alegam participar de todas as aulas no $1^{\circ}$ ano, mas no $3^{\circ}$ ano decai para $32 \%$.

O resultado quanto à participação menor do corpo discente das meninas tanto na análise do total quanto na análise estratificada compactua com indicativos da literatura. Segundo Oliver e Hamzeh (2010) e Okely et al. (2017), a falta de confiança nas suas habilidades e a dificuldade em se relacionar com os meninos, que dominam as aulas de EF, tendem a ser aspectos que desmobilizam boa parte das estudantes. Uchoga e Altmann (2016) indicam que a menor participação das meninas está relacionada ao medo de arriscar-se nas aulas, de expor-se corporalmente, "ficar sob os olhos" (vigilância) dos/as outros/as e, às vezes, defrontarse com supostas inabilidades para as práticas corporais. So, Martins e Betti (2018) citam que a menor participação feminina no conteúdo lutas nas aulas de EF estava atrelada aos seguintes fatores: (i) a associação dos/as discentes de que a luta é um conteúdo masculino; (ii) vergonha das meninas em expor supostas inabilidades e; (iii) o medo de se machucar. Esses estudos, resumidamente, ratificam o argumento de Altmann (1998) ao indicar que estudantes meninos tendem a "colonizar" e/ou "dominar" o espaço central das aulas de EF. 
Em adição, Martinelli et al. (2006) constataram que a participação nas aulas de EF de um grupo de meninas estava concatenada à obrigação, isto é, a avaliação (nota e chamada). Liz (2000) notou que os motivos das meninas solicitarem dispensa das aulas de EF é a falta de diversidade de conteúdos trabalhados, resultado que corrobora com Oliveira, Macedo e Silva (2014), que também sugerem a ampliação de conteúdos como modo de inclusão das meninas autoexcluídas. Outro aspecto a ser apontado é a falta de tematização de gênero nas aulas deste componente curricular, o que poderia sensibilizar os e as estudantes a uma mudança de atitude nas suas relações (Azzarito \& Solomon 2005; Jesus \& Devide, 2006). Para tanto, Oliveira, Jaeger e Roth (2019) sugerem diferentes estratégias para tal desconstrução, tais como: "discussões, debates, rodas de conversa, auxílio aos/as colegas que tem dificuldades, utilização de jogos mistos” (p. 92).

Por outro lado, mesmo quando as discentes se predispõem a participar das aulas, alguns meninos afetados pela subversão da masculinidade, costumam afirmá-la por meio de comentários jocosos e sexualmente pejorativos. Sem dúvidas, a violência verbal que leva ao constrangimento, à emersão de inseguranças interfere na autoexclusão de meninas (Barbosa, 2012; Altmann, 1998; van Daalen, 2005).

Todavia, além da situação de "não participação", Jacó (2012), em observação e entrevistas com estudantes de $8^{\circ}$ ano do Ensino Fundamental, apresenta que a participação discente nas aulas se dá personificada em quatro papéis: "protagonista", "figurante", "flutuante" e "excluída". Em linhas gerais, a autora afirma que observou poucas "protagonistas" (meninas), o que foi justificada pela característica das aulas. $\mathrm{Na}$ ocasião, as aulas privilegiavam momentos de prática esportiva e a demonstração de habilidades atinentes a essa prática. A característica dessa aula favorecia estudantes que possuíam experiências prévias com esportes coletivos fora da escola que, a priori, eram mais praticados pelos meninos em comparação às meninas. Nesse sentido, além da diversificação dos conteúdos da EF indicada por Jacó (2012) é de vital importância que a EF seja efetiva e intencionalmente orientada pelos/as docentes (Hills \& Croston, 2012). Historicamente, argumenta Garcia (2007), a disciplina de EF mobiliza mais os estudantes que as estudantes por ser hegemonizada pelo conteúdo esportivo, representando, como afirma Vigarello (2013), um momento privilegiado para performatização de masculinidades relacionadas à virilidade.

Azarrito e Solomon (2005) alegam que a EF escolar é marcada pela pouca preocupação do corpo docente com a participação das meninas nas aulas e, parece-nos que essa situação consiste numa "refração" daquilo que ocorre nos ambientes extraescolares. Conforme Ferreira et al. (2018), as meninas apresentam menor participação em atividades físicas e esportivas no lazer. Para Hallal et al. (2012), estima-se que ao redor do mundo, 80,3\% dos e das jovens de 13 a 15 anos não praticam o recomendado de atividade física semanal. Em particular, com relação às meninas, a estimativa é que $95 \%$ delas não atinge o nível mínimo de atividade física recomendada. Na mesma esteira, os levantamentos brasileiros demonstram que as meninas, no geral, são menos ativas que os meninos. Apenas $31,8 \%$ delas são consideradas suficientemente ativas, em contraposição aos 52,2\% dos meninos (Hallal et al., 2010). Logo, a compreensão dessa desigualdade de participação entre gêneros na EF escolar, bem como em programas extracurriculares de atividades físicas é fulcral para reverter desigualdades e constituir a equidade de gênero na participação em práticas corporais.

Faz-se necessário, ressaltar, conforme Daolio (2006) e Salvivi e Myskiw (2009), que a menor participação das estudantes nas aulas de EF não é condição sine qua non a todas as meninas. Pelo contrário, ela decorre de uma "teia de significados" tal como menciona Geertz (apud Daolio, 2006) e das interações simbólicas que meninas estabelecem com as outras meninas, com meninos, professores/as e situações em aula. Isso decorre, ademais, de uma leitura em que as diferenças culturais não se constituem como destinos inevitáveis aos quais as meninas estão fadadas (Butler, 2004). Destarte, ainda que esses discursos culturais se coloquem como obstáculos para oportunizar maiores chances de participação para os estudantes em detrimento das estudantes, as meninas têm algumas condições de agenciamentos diante deles, que são traduzidas em situações de negociação, transgressão e resistência, bem como de acomodação (Altmann, 1998).

Em vista disso, é preciso atentar-se, como inspira Charlot (2000), aos casos paradoxais, isto é, aos casos de meninas (e também meninos) que subvertem as diversas ordens estabelecidas ("generificadas"). Assim como 
ressaltam Sousa e Altmann (1999), depreendemos que as meninas possuem capacidades de agenciamento das redes de poder em que estão e que também podem se posicionar em situação dominante, uma vez que “[...] vitimá-las significaria coisificá-las, 'aprisioná-las pelo poder', desconsiderando suas possibilidades de resistência e também de exercício de dominação” (p. 59). Por essa razão, torna-se fundamental pesquisar as fontes que mobilizam as estudantes a participar das aulas de EF e que podem contribuir para que elas agenciem sua participação nas aulas. Do mesmo modo, investigar o que vem interferindo na participação inferior na maior quantidade de aulas. Por certo, questóes nesse âmbito podem representar o ensejo para futuras e interessantes pesquisas nesse mote.

\section{Sentido e mobilização das alunas: o discurso explícito e a discriminação implícita}

A mobilização, aqui representada pela participação nas aulas, é compreendida como o ato de colocar-se em movimento, em agrupar forças para ser educado. Contudo, isso só decorre se a pessoa atribuir um sentido a determinado saber e se considerá-lo de valor (importância) (Charlot, 2000; 2005). Os resultados apresentados na seção anterior demonstram que as estudantes gostam menos, atribuem menor importância e participam menos do que os estudantes das aulas de EF. Com base nesses dados, poderíamos dizer que as meninas estão em situação de fracasso escolar com a EF? Para responder esse questionamento, dialogamos com os estudos de Adriana Marrero (2007) e Bernard Charlot (2009). Segundo Marrero (2007), a instituição escolar possui algo peculiar em comparação a outros espaços, pois pela primeira vez e diferente de outros contextos, as meninas encontram a possibilidade de conhecer seus próprios talentos, esforços e realizaçóes em um local em que o comportamento entre ser menina ou menino não é o mais importante. Por este viés, a escola faz defesa formal-normativa de valores relacionados à inclusão, à universalidade, à diversidade, o que favorece um acesso ao saber supostamente igual e disponível entre gêneros. Ao mesmo tempo, este discurso é passível de crítica, haja vista idearmos que além de um discurso explícito (prescritivo-normativo), estudantes também convivem com processos discriminatórios implícitos entre meninas e meninos (dentro e fora da escola).

Baxter (1999) assinala, por exemplo, que os estudantes costumam expor mais seus conhecimentos, mesmo que de modo superficial, enquanto que as estudantes procuram demonstrá-los apenas quando possuem embasamento detalhado por meio de estudos. Esse comportamento de maior exposição dos meninos induz a um discurso em que a escola pode visualizá-los como dotados de uma "inteligência natural", enquanto as meninas podem ser descritas como "esforçadas". Na lógica desse discurso, aquilo que é considerado o jeito "efetivo" de se colocar publicamente permanece associado ao universo do masculino, de modo que um posicionamento público de meninas e mulheres tende a tomar o masculino como referência. Em consonância, Marrero (2007) destaca que, desde o ensino escolarizado, os estudantes são vistos como "herdeiros" ${ }^{5}$, perspectiva que os coloca numa posição mais "relaxada" e flexível em relação com o saber, com a escola e com a ordem institucional explícita. Por sua vez, o fato das meninas não partilharem da "voz dominante" (expressão de Baxter, 1999), demanda um comportamento fiel e sistemático à lógica discursiva explícita. Portanto, as meninas compensam essa desigualdade por meio de seus esforços acadêmicos, tornando-se as principais "defensoras e vigilantes" da ordem explícita, justamente porque prescindem dela como ponto de referência (Marrero, 2007).

Este descompasso entre o discurso explícito e a discriminação implícita, também pode ser percebido no contexto específico da disciplina escolar de EF. No âmbito explícito, em proposições teórico-metodológicas da área (Coletivo de autores, 2009; Kunz, 2010; Betti, 2009) e em documentos curriculares oficiais da EF (Brasil, 1998; 2017), advoga-se que esse componente curricular deve lidar com a apreciação e apropriação crítica dos elementos da cultura de movimento em respeito a princípios de inclusão, diversidade, alteridade, universalidade e equidade de gênero. Do mesmo modo, no âmbito implícito nota-se, juntamente aos indicativos da literatura, que no cotidiano da EF escolar há uma série de discriminações do tipo: (i) separação 
das turmas/classes de EF ou atividades por critério de sexo (critério biologicista); (ii) privilégio de práticas esportivas coletivas (pobreza e repetição de conteúdos da EF) que incitam o exibicionismo daqueles que já possuem experiência nas referidas modalidades, que, via de regra, são em grande maioria estudantes meninos; (iii) generificação de conteúdos da EF (por exemplo: meninos jogam futebol e meninas jogam voleibol); (iv) violência verbalizada por meninos às meninas (ao corpo, à habilidade); (v) a vigilância das atitudes das estudantes pelos meninos; (vi) a inferiorização das meninas pressuposta pelos professores (ou professoras) ao separarem as turmas entre meninos e meninas, sob o argumento de uma suposta ausência de habilidades ou de força por parte delas.

Em síntese à discussão sobredita, há a existência de uma ambiguidade na escola entre os discursos explícitos e implícitos que se reproduzem nas aulas de EF. Scraton (2018) sugere que a constituição de uma pedagogia crítico-reflexiva na EF escolar precisa atentar-se para as diversas desigualdades que permeiam os cotidianos escolares. Considerando que experiências discriminatórias (de gênero, raça, geração, religião etc.) estão largamente presentes no contexto das oportunidades de acesso e permanência às práticas corporais torna-se de vital importância que a EF escolar comprometida com os ideais de uma instituição escolar republicana e democrática (González \& Fensterseifer, 2009; 2010) se converta numa disciplina escolar sensível, crítica e que engendre proposições educativas encorajadas por vários marcadores sociais, entre eles o marcador de gênero, como também argumenta Scraton (2018).

Embasado nos dados da presente pesquisa duas considerações merecem destaque. Primeiramente, o menor gosto e participação das estudantes nas aulas de EF era um resultado esperado, pois corrobora com a literatura. Com efeito, considerando o cenário escolar como fonte de discriminações implícitas e que a EF reproduz (e, muitas vezes, reforça) a desigualdade de gênero, a expectativa inicial era a de contraste muito grande entre o gosto, importância e participação entre os e as estudantes, sendo que as últimas teriam os resultados menores. Porém, e esta é a segunda consideração, não podemos afirmar que elas, as estudantes, desgostam, não dão importância e não participam das aulas. Posto isso, é importante indicar que, embora os resultados da pesquisa sinalizem a prevalência ("domínio") dos estudantes nas aulas e as meninas se encontrem em situação de "fracasso escolar" na EF, não é essa a interpretação que uma análise mais atenta dos resultados indica. Resumidamente, as meninas também gostam, dão importância e participam das aulas de EF e, este resultado, abre precedente para futuras investigações com essa temática.

Nesse sentido, Marrero (2007) nos dá uma pista para melhor compreensão deste fenômeno:

(...) con su obediencia estricta a lo escolar, estas niñas terminan, paradójicamente, transgrediendo las bases mismas del orden social implícito, al obligar a los docentes y a sus pares a reconocerlas como sujetos por derecho propio, aunque paguen, por su transgresión el precio del rechazo (p.36).

Isto é, parece que a relação positiva das meninas com a EF se dá pelo cumprimento às questões explícitas do sistema escolar e da disciplina.

Por sua vez, as questões implícitas segregacionistas parecem favorecer a "colonização" dos meninos (herdeiros), bem como suas relações de positividade com a disciplina. Em todo caso, algumas investigações já apontaram que uma grande parte das meninas participa da EF concatenada à obrigação (Martinelli et al., 2006). Todavia, a obediência à ordem explícita pode contribuir para que as estudantes subvertam a discriminação implícita na EF. Isso significa, portanto, que não podemos analisar a obediência tão-somente como um ato de "docilidade", mas também como uma posição estratégica que as meninas podem aderir à escolarização como parte de um projeto de vida, como aponta o estudo de Carvalho (2015) e Charlot (2009). Enfim, o debate sobre a noção de "obediência-subversiva" ideada como um projeto engendrado (conscientemente ou não) por estudantes meninas para lograr “espaços de fala”, direitos sociais (participação) e criar rupturas numa EF escolar permeada por discursos generificados pode ser uma interessante hipótese de trabalho. 


\section{Conclusão}

Atribuir importância, gostar e participar são ações que ocorrem de modo diferente entre as e os estudantes. A compreensão de como alunas e alunos se relacionam - isto é, atribuem gosto, importância e declaram participar das aulas - com os saberes e conhecimentos da EF pode contribuir para uma EF mais sensível, crítica, com proposições efetivas, bem fundamentadas, contínuas e consistentes rumo à equidade de gênero nas aulas desse componente curricular. A equidade, neste sentido, indica que diferenças e preferências de gênero existem e devem ser reconhecidas e respeitadas, porém as desigualdades instituídas ora nos discursos (implícitos ou explícitos), ora nas práticas da EF escolar devem ser "avultadas", problematizadas e combatidas. Em vista disso, é vital a criação de mecanismo de interlocução dos/as docentes com as e os estudantes.

Quanto ao objetivo deste artigo de compreender a interferência do marcador de gênero nas relações de meninos e meninas com a EF escolar, resumidamente, os resultados do estudo indicam que há uma distinção na ordem de gosto de estudantes meninas e meninos para com a disciplina de EF sendo que, neste sentido, a preferência de gosto das meninas não é unânime. Contudo, não é possível afirmar que elas desgostam da EF. Ainda em relação ao gosto, no decorrer do EM, tanto as estudantes quanto os estudantes tendem a "perdêlo", aumentando o índice de quem declara "gostar pouco" da EF escolar. Vale ressaltar que, do mesmo modo que há meninas que gostam, há meninos que desgostam da EF indicando, assim, a noção de masculinidades e feminilidades plurais. O reconhecimento dessa pluralidade é fundamental para uma EF com maior equidade de gênero.

No que concerne à ordem de importância, os resultados indicam um decréscimo ao longo do EM, sendo que a perda de importância é mais acentuada entre os estudantes. Possivelmente, esse fato possa ser creditado à perda de interesse dos meninos pela escolarização, enquanto as meninas tendem a planear projetos de vida associados à escolarização. Todavia, esses resultados precisam ser confrontados com resultados de outros estudos futuramente. $\mathrm{Na}$ análise comparada dos resultados da atribuição de gosto (relação de prazer) com a importância (juízo de valor), notamos que não há a relação de causalidade entre eles. De fato, mesmo que a maioria dos e das estudantes declarasse gostar da EF, seus juízos de valor em relação à importância da disciplina são intermediários, atrás da Matemática e Língua Portuguesa; sobretudo entre as meninas, que além destas disciplinas, mencionam a Geografia e Biologia.

Em relação à participação, a maioria dos e das estudantes participa de "todas" ou da "maioria" das aulas. Porém, notamos que o marcador gênero aponta menor participação das meninas, tanto em número absoluto ou estratificado por cada ano escolar. A pesquisa indica que esse resultado pode ter sido motivado por uma série de fatores: desconfiança das estudantes em relação às suas habilidades, medo de se expor corporalmente ("ficar sob os olhos de outros", independente se meninos ou meninas), defrontar inabilidades e/ou sentirse num ambiente de "dominação" ou "colonização" masculina. Todavia, vale destacar que além do gosto em si, a participação das meninas nas aulas de EF, também é atrelada à obrigatoriedade (nota e chamada) e/ou associada às ações de negociação, transgressão e resistência; em busca de uma participação efetiva, de "protagonismo" nas aulas. Neste último caso, podemos aventar a noção de "obediência-subversiva" em que, numa visão mais idealista e racionalista, a participação tem intenções explícitas de subversão do ideário de "dominação" masculina das aulas de EF.

$\mathrm{O}$ atual estudo indica ainda, resumidamente, que o marcador de gênero nos permite analisar que a escola e a EF são ambiguamente permeadas pelo discurso explícito de igualdade de condições (como instituição republicana e democrática) e por discursos segregacionistas de gênero. Neste aspecto, o papel docente ganha extrema relevância, pois serão esses homens e mulheres que imbuídos de intencionalidade pedagógica poderão problematizar a desigualdade de gênero junto aos estudantes. Quanto aos estudantes (meninas, meninos e outros) de EF no EM participantes ou não dessa pesquisa, o presente estudo enceta, e em alguns casos reitera, o convite para co-construírem uma EF com maior equidade de gênero e, para tanto, é fundamental estar disposto a participar das aulas e dialogar com os docentes. Vale a pena citar que muitos 
professores e professoras têm realizado ações (rodas de conversa, autoavaliações, conversas informais etc.) para criar campos de interlocução (diálogos) pelos quais meninos, meninas e outros, podem problematizar e discutir, entre outras coisas, as desigualdades de gênero dentro e/ou fora do contexto da EF escolar.

De resto, os limites do estudo abriram brechas para levantarmos questões que podem orientar investigações nessa temática. Em primeiro, lugar faz-se necessário investigar os casos paradoxais, buscar compreender as fontes de sentido e mobilização dos e das estudantes (os "porquês") para a EF escolar. Vale a pena citar também, a importância de pesquisas qualitativas com delineamentos metodológicos que "deem ouvidos" aos e às discentes (grupos focais, entrevistas, etc.). Problemáticas de pesquisa podem ser orientadas a partir das seguintes questões: o que leva as meninas a gostarem, atribuírem importância e participarem das aulas de EF mesmo frente às discriminações, às vezes, explícitas e com mais recorrência implícitas? Como elas negociam e lidam com essas desigualdades, a fim de garantir seu direito de participar equitativamente da EF? Quais processos de mediação pedagógica mais adequados para lidar com a mobilização de meninas e meninos? Certamente, essas questões podem servir de base para outros projetos de pesquisa com o tema.

\section{REFERÊNCIAS}

Altmann, H. (1998). Rompendo fronteiras de gênero: Marias (e) homens na EF. Dissertação (Mestrado) - Curso de Mestrado em Educação, Faculdade de Educação, Universidade Federal de Minas Gerais, Belo Horizonte.

Azzarito, L., \& Solomon, M. A. (2005). A reconceptualization of physical education: The intersection of gender/race/ social class. Sport, Education and Society, 10(1), 25-47. https://doi.org/10.1080/135733205200028794

Barbosa, J. P. (2012). Aulas de educação física no ensino médio mistas e separadas por sexo: quais as implicações no comportamento e aproveitamento dos alunos de uma escola estadual da cidade de Porto Alegre. TCC (Graduação) - Curso de Educação Física, Universidade Federal do Rio Grande do Sul, Porto Alegre.

Baxter, J. A. (1999). Teaching girls to speak out: the female voice in public contexts. Language and Education, 13(2), 81-98.

Betti, M., \& Liz, M. T. F. (2003). Educação física escolar: a perspectiva de alunas do ensino fundamental. Motriz, 9(3), $135-142$.

Betti, M. (2009). Educação Física e sociedade: a Educação Física na escola brasileira. 2. ed. São Paulo: Hucitec.

Brasil. Ministério da Educação e Desporto. (1998). Secretaria do Ensino Fundamental. Parâmetros curriculares nacionais: educação fisisica- $5^{a}$ a $8^{a}$ séries. Brasília: MEC, SEF.

Brasil. Ministério da Educação. (2017). Base Nacional Comum Curricular. Brasília: MEC.

Burawoy, M. (2010). O marxismo encontra Bourdieu. Organização de Ruy Braga. Tradução de Fernando Rogério Jardim. Campinas, SP: Editora da UNICAMP.

Butler, J. (2004). Problemas de gênero: feminismo e subversão da identidade. Rio de Janeiro: Civilização Brasileira.

Carvalho, M. (2015). The influence of family socialisation on the success of girls from poor urban communities in Brazil at school. Gender and Education, 27(6), 583-598. https://doi.org/10.1080/09540253.2015.1071784

Charlot, B. (2000). Da relação com o saber: elementos para uma teoria. Porto Alegre: Artmed.

Charlot, B. (2005). Relação com o saber, Formação de Professores e Globalização: questões para a educação hoje. Porto Alegre: ARTMED.

Charlot, B. (2009). A relação com o saber e a discriminação de gênero na escola, in Marrero, A. \& Mallada, N. La universidad transformadora: elementos para uma teoria sobre Educación y Género. FCS-UR-CSIC.

Coletivo de autores. (2009). Metodologia do ensino de educação fisica. 2. ed. rev. São Paulo, SP: Cortez.

Corder, K., Sharp, S. J., Atkin, A. J., Griffin, S. J., Jones, A. P., Ekelund, U., \& van Sluijs, E. M. (2015). Change in objectively measured physical activity during the transition to adolescence. British journal of sports medicine, 49(11), 730-736. http://dx.doi.org/10.1136/bjsports-2013-093190 
van Daalen, C. (2005). Girls' experiences in physical education: Competition, evaluation, \& degradation. The Journal of School Nursing, 21(2), 115-121. https://doi.org/10.1177/10598405050210020901

Daolio, J. (2006). Cultura: Educação Física e futebol. 3. ed. Campinas, SP: Editora da Unicamp.

Del Castillo-Andrés, Ó., Campos-Mesa, M. C. and Ries, F. (2013). Gender equality in Physical Education from the perspective of Achievement Goal Theory. Journal of Sport and Health Research, 5(1), 57-70. Recuperado de htt p://www.journalshr.com/papers/Vol\%205_N\%201/V05_1_4.pdf

Dornelles, P. G., \& Fraga, A. B. (2009). Aula mista versus aula separada? Uma questão de gênero recorrente na educação física escolar. Revista Brasileira de Docência, Ensino e Pesquisa em Educação Física, 1(1), 141-156.

Ferreira, M. L. S.; Graebner, L. \& Matias, T. S. (2014). Percepção de alunos sobre as aulas de EF no EM. Pensar a prática, 17(3). Recuperado de https://www.revistas.ufg.br/fef/article/view/25587/17108.

Ferreira, R. W., Varela, A. R., Monteiro, L. Z., Häfele, C. A., Santos, S. J. D., Wendt, A., \& Silva, I. C. M. (2018). Sociodemographic inequalities in leisure-time physical activity and active commuting to school in Brazilian adolescents: National School Health Survey (PeNSE 2009, 2012, and 2015). Cadernos de saude publica, 34, e00037917. http://dx.doi.org/10.1590/0102-311x00037917

Flick, U. (2009). Desenho da pesquisa qualitativa. Porto Alegre: Artmed.

Garcia, M. (2007). Représentations « genrées » et sexuation des pratiques circassiennes en milieu scolaire. Sociétés \& Représentations, 24(2), 129-143. https://doi.org/10.3917/sr.024.0129

Gil, A. C. (2010). Como elaborar projetos de pesquisa. 5. ed. São Paulo, SP: Atlas.

Goellner, S. V. (2003). Bela, maternal e feminina: imagens da mulher na Revista Educação Physica. Ijuí: Unijuí.

Goellner, S. V. (2005). Mulheres e futebol no Brasil: entre sombras e visibilidades. Revista brasileira de educação fisica e esporte, 19(2),143-151. https://doi.org/10.1590/S1807-55092005000200005

Goellner, S. V. (2013). Gênero e esporte na historiografia brasileira: balanços e potencialidades. Tempo, 19(34), 45-52. https://doi.org/10.5533/TEM-1980-542X-2013173405

González, F. J., \& Fensterseifer, P. E. (2009). Entre o "não mais" e o "ainda não": pensando saídas do não-lugar da EF escolar I. Cadernos de formação RBCE, I(1). Recuperado de http://rbce.cbce.org.br/index.php/cadernos/artic le/view/929.

González, F. J., \& Fensterseifer, P. E. (2010). Entre o "não mais" e o "ainda não": pensando saídas do não-lugar da EF escolar II. Cadernos de formação RBCE, 1(2). Recuperado de http://revista.cbce.org.br/index.php/cadernos/ar ticle/view/978.

Hallal, P. C., Knuth, A. G., Cruz, D. K. A., Mendes, M. I., \& Malta, D. C. (2010). Prática de atividade física em adolescentes brasileiros. Ciência \& Saúde Coletiva, 15, 3035-3042. Recuperado de https://www.scielo.br/pdf/ csc/v15s2/a08v15s2.pdf.

Hallal, P. C., Andersen, L. B., Bull, F. C., Guthold, R., Haskell, W., Ekelund, U., \& Lancet Physical Activity Series Working Group. (2012). Global physical activity levels: surveillance progress, pitfalls, and prospects. The lancet, 380(9838), 247-257. https://doi.org/10.1016/S0140-6736(12)60646-1

Hernández-Álvarez, J. L., López-Crespo, C., Martínez-Gorroño, M. E., López-Rodríguez, Á., \& Álvarez-Barrio, M. J. (2010). Percepción del alumnado sobre los comportamientos instructivos del profesorado y satisfacción con la Educación Física:؛ una cuestión de género?. Movimento, 16(4), 209-225. Recuperado de https://www.redalyc. org/articulo.oa?id=115316963012.

Hills, L. A. \& Croston, A. (2012). 'It should be better all together': exploring strategies for 'undoing' gender in coeducational physical education. Sport, Education and Society, 17(5), 591-605. https://doi.org/10.1080/1357 3322.2011 .553215

Houaiss, A. (2009). Dicionário eletrônico Houaiss da lingua portuguesa, Rio de Janeiro: Ed. Objetiva.

Jacó, J. F. (2012). Educação física escolar e gênero: diferentes maneiras de participar das aulas. Dissertação (Mestrado), Programa de Pós-Graduação em Educação Física, Unicamp, Campinas. 
Jacoby, L. F., \& Goellner, S. V. (2020). Educação Física e questões de gênero: motivos para a escolha de modalidades esportivas por estudantes do ensino médio de uma escola militar. Motrivivência, 32(62), 01-19. https://doi.org $/ 10.5007 / 2175-8042.2020 \mathrm{e} 67164$

Jesus, M. L., \& Devide, F. P. (2006). Educação física escolar, co-educação e gênero: mapeando representações de discentes. Movimento, 12(3), 123-140. https://doi.org/10.22456/1982-8918.2912

Kunz, E. (2010). Transformação didático-pedagógica do esporte. 7.ed. Ijuí: Unijuí.

Leitão, A. S. P. (2019). Ética e educação fisica escolar: uma proposta de intervenção no ensino fundamental. Tese (Doutorado em Educação Física), Faculdade de Educação Física, Unicamp, Campinas.

Liz, L. C. (2000). Dispensa das aulas de EF: os motivos de alunas do EM. Monografia (Especialização em EF e Esporte para Crianças e adolescentes), UNESP.

López, I. D. (2014). Marcadores de género en la infancia. Educación y Ciencia, (17). Recuperado de https://revistas.u ptc.edu.co/index.php/educacion_y_ciencia/article/view/5280

Marconi, M. A. \& Lakatos, E. M. (2017). Técnicas de pesquisa: planejamento e execução de pesquisas; amostragens e técnicas de pesquisa; elaboração, análise e interpretação de dados. 8. ed., São Paulo, SP: Atlas.

Marrero, A. (2007). \#Hermione en Hogwarts o sobre el éxito escolar de las niñas\#, in Marrero, A. (Ed.), Educación y Modernidad hoy. Montevideo, Germania-Ediciones de la Banda Oriental.

Martinelli, C. R.; Merida, M., Rodrigues, G. M., Grillo, D. E., \& de Souza, J. X. (2006). Educação física no ensino médio: motivos que levam as alunas a não gostarem de participar das aulas. Revista Mackenzie de Educação Física e Esporte, 5(2). Recuperado de http://editorarevistas.mackenzie.br/index.php/remef/article/view/1288.

Mattos, M.Z.D; Jaeger, A. A. (2015). Bullying e as relações de gênero presentes na escola. Movimento, 21(2), 349-361 https://doi.org/10.22456/1982-8918.48001

Okely, A. D., Lubans, D. R., Morgan, P. J., Cotton, W., Peralta, L., Miller, J., Batterham, M. \& Janssen, X. (2017). Promoting physical activity among adolescent girls: the girls in sport group randomized trial. International Journal of behavioral nutrition and physical activity, 14(1), 81. https://doi.org/10.1186/s12966-017-0535-6

Oliveira, F., Macedo, R., \& Silva, A. (2014). Fatores associados a participação das alunas nas aulas de Educação Física: uma questão de gênero?. ACTA Brasileira do Movimento Humano, 4(5). Recuperado de http://www.periodico s.ulbra.br/index.php/actabrasileira/article/view/3081/2271.

Oliveira, M. C., Jaeger, A. A., \& Roth, V.J. S. (2019). Estereótipos de gênero e educação física: diálogos com estudantes de Ensino Médio. Arquivos em Movimento, 15(1), 75-96. Recuperado de https://revistas.ufrj.br/index.php/am /article/view/23083.

Oliver, K. L., \& Hamzeh, M. (2010). “The Boys Won't Let Us Play” Fifth-Grade Mestizas Challenge Physical Activity Discourse at School. Research Quarterly for Exercise and Sport, 81(1), 38-51. https://doi.org/10.1080/027013 67.2010.10599626

Programa das Nações Unidas para o Desenvolvimento (PNUD) (2017). Relatório de Desenvolvimento Humano Nacional - Movimento é vida: Atividades Físicas e Esportivas pata Todas as Pessoas. Recuperado de http://movi mentoevida.org/wp-content/uploads/2017/09/PNUD_RNDH_completo.pdf

Salvivi, L., \& Myskiw, M. (2009). As manipulações do corpo na representação da imagem social de alunas nas aulas de Educação Física. Pensar a Prática, Goiânia, 12(3), 1-11. Recuperado de https://www.revistas.ufg.br/fef/arti cle/download/6515/5974?inline $=1$.

Scott, J. (1995). Gênero: uma categoria útil de análise histórica. Educação \& realidade, 20(2). Recuperado de https:/ /www.seer.ufrgs.br/educacaoerealidade/article/viewFile/71721/40667

Scraton, S. (2018). Feminism (s) and PE: 25 years of Shaping Up to Womanhood. Sport, Education and Society, 23(7), 638-651. https://doi.org/10.1080/13573322.2018.1448263

So, M. R., Martins, M. Z., \& Betti, M. (2018). As relações das meninas com os saberes das lutas nas aulas de Educação Física. Motrivivência, 30(56), 29-48. Recuperado em https://periodicos.ufsc.br/index.php/motrivivencia/artic le/viewFile/2175-8042.2018v30n56p29/37982 
Sousa, E. S. D., \& Altmann, H. (1999). Meninos e meninas: expectativas corporais e implicações na educação física escolar. Cad. Cedes, 52-68. Recuperado de https://www.scielo.br/pdf/ccedes/v19n48/v1948a04.pdf.

Uchoga, L. A. R., \& Altmann, H. (2016). Educação física escolar e relações de gênero: diferentes modos de participar e arriscar-se nos conteúdos de aula. Revista Brasileira de Ciências do Esporte, 38(2), 163-170. https://doi.org/1 $0.1016 /$ j.rbce.2015.11.006

Vigarello, G. (2013). Virilidades esportivas, in Corbin, A.; Courtine, J.-J.; Vigarello, G. História da Virilidade. Volume 3 -A virilidade em crise? Séculos $X X-X X I$. Petrópolis: Vozes.

Wenetz, I., \& Stigger, M. P. (2006). A construção do gênero no espaço escolar. Movimento, 12(1). 59-80. Recuperado de https://www.lume.ufrgs.br/bitstream/handle/10183/20264/000567031.pdf?sequence $=1$

Zamboni, M. (2013). A sessão de desenho de modelo nu: produção artística e marcadores sociais da diferença. Sexualidad, Salud y Sociedad-Revista Latinoamericana, (15), 62-85. Recuperado de https://www.e-publicacoes .uerj.br/index.php/SexualidadSaludySociedad/article/view/5239/6182.

\section{Notas}

1 O primeiro autor demonstra agradecimento especial ao IFSULDEMINAS por fornecer condiçóes e incentivos de qualificação para o desenvolvimento deste manuscrito. Também agradecemos os membros participantes do Grupo de Estudos Socioculturais, Históricos e Pedagógicos da Educação Física (DEF-Unesp/Bauru) que contribuíram com a consolidação deste trabalho.

2 Aqui tratamos gênero como um marcador que expressa a forma pela qual percebemos e classificamos as diferenças e as desigualdades entre as pessoas não como algo natural, ao invés, como algo "naturalizado" conforme discute Bourdieu (Burawoy, 2010). Sendo assim, cada indivíduo partilha de certas características que são hierarquizadas (atravessadas por relações de poder) nas interações sociais que estabelece com os outros. Destarte, gênero, raça, classe social, sexualidade, geração etc., são exemplos, de marcadores sociais de diferença que produzem e reproduzem desigualdades de forma integrada, simultânea e articulada, indicando que pode haver experiências de vida inteiramente distintas entre as pessoas, sobretudo, aquelas que não compartilham das mesmas características (Zamboni, 2013).

3 Dados coletados em 2013 como parte do projeto de pesquisa "Os saberes da Educação Física nas perspectivas dos alunos: diagnóstico e interlocuções" desenvolvido no âmbito do Grupo de Estudos Socioculturais, Históricos e Pedagógicos da Educação Física (CNPq), vinculado ao Departamento de Educação Física da Faculdade de Ciências da UNESP campus de Bauru, sob responsabilidade do Prof. Dr. Mauro Betti.

4 Cabe destacar que a noção de desejo não se encontra amplamente aprofundada na obra de Charlot (2009), de modo que a tomamos, de forma simples, como uma disposição pessoal para uma ação.

5 No sentido de pessoa que dá continuidade a uma tradição (Houaiss, 2009). 